\title{
İlköğretim Çağındaki Öğrencilerin Sosyal Beceri Düzeylerinin Spor Yapma Durumlarına Göre İncelenmesi: İstanbul İli Örneği
}

\author{
Suzan DAL ${ }^{1}$, Selin BAİKOĞLU ${ }^{2 *}$ \\ ${ }^{1}$ İstanbul Üniversitesi, Yabancı Diller Yüksekokulu, https://orcid.org/ 0000-0002-7732-9846 \\ ${ }^{2}$ İstanbul Üniversitesi- Cerrahpaşa, Spor Bilimleri Fakültesi, https://orcid.org/ 0000-0002-6036-8945
}

Orijinal Makale

Gönderi Tarihi: 27.11.2019 Kabul Tarihi: 25.12.2019

DOI: $10.30769 /$ usbd.651943

Online Yayın Tarihi: 31.12.2019

\section{$\ddot{\mathbf{O} z}$}

Sporun çocuğun sosyal, duygusal, motorsal ve psiko-sosyal gelişimi üzerinde çok önemli bir yeri vardır. Çocukların günlük yaşamında sosyal becerilerinin düzenli olarak katılım sağladıkları sportif faaliyetlerle nasıl etkilendiğini belirlemek çalışmanın amacını oluşturmatadır. Çalışmanın evrenini 2018-2019 eğitim öğretim yılında, özel bir ilköğretim okulunun ortaokul bölümünde okuyan yaşları 9-12 aralığında olan 114 çocuk oluşturmaktadır. Demografik bilgilerin dışında çocuklara sosyal beceri düzeylerini ölçmek için sosyal beceri ölçeği, uygulanmıştır. Verilerin analizinde frekans, t-testi, kruskal-wallis kullanılmıştır. Anlamlılık düzeyi $\mathrm{p}<0,05$ olarak kabul edilmiştir. Çalışma sonucunda öğrencilerin sosyal beceri düzeylerinin $\mathrm{x}=58,2( \pm 9,11)$ olduğu belirlenmiștir. Öğrencilerin spor yapma durumlarına göre sosyal beceri düzeylerinde istatistiksel açıdan anlamlı farklılığa rastlanmamasına rağmen spor yapan öğrencilerin sosyal becer düzeyleri daha yüksek bulunmuştur. Ayrıca öğrencilerin sınıf ve cinsiyet değişkenlerine göre sosyal beceri düzeylerinde istatistiksel açıdan anlamlı farklılıklara rastlanmamıștır.

Anahtar kelimeler: Spor, Sosyal beceri, Çocuk.

\section{Examination of Social Skill Levels of Primary School Students According to Their Status of Doing Sports: İstanbul City Example}

\begin{abstract}
Sports has an important role in the child's social, emotional, motor and psycho-social development. The aim of the study is to determine how social skills of children are affected by the sports activities they regularly participate in. The population of the study consists of 114 children aged between 9-12 years, studying at a private secondary school in the 2018-2019 academic year. In addition to the demographic information, social skill scale was applied to the children in order to measure their social skill levels. Frequency, t-test and kruskal-wallis were used for data analysis. Significance level was accepted as $\mathrm{p}$ $<0.05$. As a result of the study, it has been determined that the social skill levels of the students were $x=58.2( \pm 9.11)$. Although there was no statistically significant difference in the social skill levels of the students according to their status of doing sports, the social skill levels of the students doing sports were found to be higher. In addition, no statistically significant differences were found in social skill levels of students according to class and gender variables.

Keywords: Sports, Social skill, Child.
\end{abstract}

* Sorumlu Yazar: Selin BAİKOĞLU, E-posta: selinbaikoglu@gmail.com 


\section{GíRiş}

Her ebeveyn çocuklarının fiziksel, duygusal ve sosyal yönden yeterli bir birey olarak yetişmesini istemektedir. Fiziksel etkinliklere katılım sosyal bir ortam içerisinde gerçekleştiği için fiziksel, sosyal, duygusal ve motorsal gelişimini önemli derecede etkilemektedir. Son zamanlarda yapılan araştırmalarda çocukların spora katılım oranlarının azaldığı bildirilmiştir (Strauss et al., 2001). Türkiye genelinde 6-11 yaş grubu çocukların \% 58.4'ü düzenli olarak egzersiz yapmamaktadır. (TC Sağlık Bakalığı, 2014). Türkiye sağlık bakanlığının 2011 yılında yaptığı proje kapsamında çocukların fiziksel aktivite durumlarını değerlendirmek amacıyla herhangi bir spor kulübünde spor yapma durumu sorgulanmıştır. Çocukların çok düşük bir oranda (\%16.9'unun) bir spor kulübünde spor yaptığı belirlenmiştir. (TC Sağlık Bakanlığı, 2011). Sportif alışkanlıklar çocukluk çağında kazandırılması gereken bir aktivitedir. Özellikle 7-12 yaşları arasında gelişim sürecinde olan çocukların sporu yaşam boyu devam ettirecekleri bir aktivite olarak benimsemeleri için önemli bir dönem olarak kabul edilmektedir. Düzenli sportif faaliyet içerisinde olmak çocuğun motorik gelişiminin artmasına, benlik saygısının gelişmesine ve çevresiyle sosyal iletişim becerisi kazanmasına olanak sağlayacaktır (Orhan, 2019). Sosyal becerilerin gelişmesinde sorun yaşayan çocuklar ise, hayatları boyunca kişilerarası ilişkilerde, mesleki yaşamlarında, duygusal-davranışsal alanlarında ve öğrenim süreçlerinde çeşitli problemlerle karşılaşmaktadırlar (Çetin vd., 2003).

Sosyal iletişim becerileri, sosyal farkındalığın, kendine güvenin ve başarılı sosyal uyumumun kişilerarası ilişkilerde uygun biçimde kullanımını ifade eder. Walker ve McConnell (1995), sosyal becerileri, öğretmenler, aile üyeleri ya da akranlarca yapılması istenilen sosyal görevleri yerine getirmek için kullanılan stratejiler olarak tanımlamıştır (Walker and McConnel, 1995). Çocukların yaşıtlarıyla arkadaşlık kurabilmesi ve kendini sözel ve sözsüz davranışlar yoluyla ifade edebilmesi oldukça önemlidir. Sosyal iletişim becerileri, bu aşamada devreye girmektedir. Çocukların bu becerilerini ilk olarak aktif şekilde kullandıkları yer okuldur. Çocukların zamanlarının çoğunu geçirdikleri okul ortamı uygun toplumsal davranış biçimlerinin kazandırılabilecekleri ve sergileyebilecekleri bir sosyal çevredir. Sosyal becerilerini geliştirilmeleri, çocukların güçlü ve olumlu arkadaş ilişkileri geliştirmelerine, akademik başarılarının artmasına yardımcı olmaktadır. Aynı zamanda gelişen sosyal yeterlilik çocukların becerilerinin gelişmesine olanak sağlamaktadır (Ergin, 2004).

Toplumun temel taşlarını çocuklar oluşturmaktadır. Çocuklara aktif yaşam tarzının kazandırılması, sosyal ve duygusal gelişiminin iyi olması ve bu iyiliğin muhafaza edilmesi geleceğin sağlıklı toplumunu oluşturmak açısından büyük bir yatırım olacaktır. Düzenli katılım sağlandığında fiziksel aktivitenin çocukların sosyal beceri ilişkilerinde olumlu etkilerinin olacağı çalışmamızın hipotezini oluşturmaktadır. Ayrıca elde ettiğimiz araştırma sonuçları doğrultusunda çocukların günlük zamanlarında sosyal ilişkilerinin düzenli olarak katılım sağladıkları sportif faaliyet içerisinde olan-olmayan çocuklar arasında incelenmesi çalışmamızın amacını oluşturmaktadır. 


\section{YÖNTEM}

\section{Araștırma Modeli}

Çalışmanın modeli betimleyici, ilişkisel tarama modeline uygun olarak yapılmıştır.

\section{Çalışma Grubu}

Çalışmamızın evrenini 2018-2019 eğitim öğretim yılında tesadüfi örneklem yolu ile belirlenen, özel bir ilköğretim okulunun ortaokul bölümünde okuyan yaşları 9-12 aralığında olan 114 çocuk oluşturmaktadır.

\section{Veri Toplama Aracı}

Çocuklara sosyal beceri düzeylerini ölçmek amacıyla anket uygulanmıştır. Öğrencilerin sosyal becerilerinin değerlendirilmesi için Kocayörük (2000) tarafından geliştirilen Sosyal beceri ölçeği kullanılmıştır. Ölçek ilköğretim öğrencilerinin göz teması kurma, merhaba-iyi günler dileme, dinlenme, konuşmayı başlatma, konuşmayı sürdürme, soru sorma, teşekkür etme, kendini tanıtma, izin isteme, iltifat etme, gruba katılma, yardım isteme, özür dileme, ikna etme, iş bölümüne uyma, grup sorumluluğunu yerine getirme ve kendini ödüllendirme davranışlarının gelişimini ölçmek amacıyla geliştirilmiş bir ölçektir. Ölçek 20 maddeden oluşmakta ve her madde dörtlü likert türündeki sorulardan oluşmaktadır ve çocukların vericeği cevaplar 1 (Hiç), 2(Bazen), 3 (Genelde) ve 4 (Tamamen) şeklindedir.

Ölçekten elde edilen puanlar 20-80 arasındadır. Ölçekten alınabilecek yüksek puan, bireyin sosyal beceri gelişiminin olumlu olduğunu ifade etmektedir. Kocayörük (2000) tarafindan ölçeğin iç tutarlılığını belirlemek için Cronbach-Alfa Güvenilirlik katsayısı hesaplanmış ve .75 olarak bulunmuştur.

\section{Kişisel Bilgi Formu}

Çocukların yaşları, cinsiyetleri, sınıfları, düzenli olarak spora katılıyor/katılmıyor olma durumları çalışmamızın demografik özelliklerini oluşturmaktadır.

\section{Ölçeği Uygulamada Kullanılan İşlem Yolu}

Çocuklar ölçeği öğretmenleri ya da bir araştırmacının gözetiminde kendileri okuyarak doldurmuşlardır. Anlamlandırmakta güçlük çektikleri ölçek maddelerinde araştırmacı tarafından açıklama yapılarak çocuklar bilgilendirilmiştir. Verdikleri yanıtlar işaretlenerek doldurulmuştur.

\section{Verilerin Analizi}

Anketlerin uygulanması sonucunda elde edilen verilerin analizi spss paket programıla değerlendirilmiştir. Demografik bilgiler ve anket sorularından elde edilen cevaplar çalışmanın değişkenleri olarak kaydedilmiştir. Elde edilen sonuçların değerlendirilmesinde verilerin normal dağılıp, dağılmadığını öğrenmek için basıklık (kurtosis) ve çarpıklık (skewness) değerlerine bakılmıştır. Veriler normal dağılım göstermektedir. Verilerin analizinde demografik bilgiler için frekans analizi yapılmıştır. İki değişkenli veriler için t-testi, ikiden fazla değişken için ise anova analizleri kullanılmıştır. Anlamlılık düzeyi $\mathrm{p}<0,05$ olarak kabul edilmiştir. 


\section{BULGULAR}

Araştırmanın bu bölümünde istatistiksel analizler neticesinde elde edilen verilere ilişkin bulgu ve yorumlara yer verilmiştir. Katılımcıların tanımlayıcı istatistikleri tablo 1'de verilmiştir.

Tablo 1. Katılımcıların kişisel özelliklerine ilişkin tanımlayıcı istatistikler

\begin{tabular}{|c|c|c|c|c|}
\hline & & Frekans & Yüzde & Geçerli yüzde \\
\hline \multirow{2}{*}{ Cinsiyet } & Kadın & 57 & 50,0 & 50,0 \\
\hline & Erkek & 57 & 50,0 & 50,0 \\
\hline \multirow{4}{*}{ Sinif } & 5 & 23 & 20,2 & 20,2 \\
\hline & 6 & 28 & 24,6 & 24,6 \\
\hline & 7 & 34 & 29,8 & 29,8 \\
\hline & 8 & 29 & 25,4 & 25,4 \\
\hline \multirow{2}{*}{$\begin{array}{l}\text { Spor yapma } \\
\text { durumu }\end{array}$} & Evet & 69 & 60,5 & 60,5 \\
\hline & Hayır & 45 & 39,5 & 39,5 \\
\hline
\end{tabular}

Tablo 1'de öğrencilerin \%50'sinin kadın, \%50'sinin erkek olduğu \%20'sinin 5. sinıf, \%24,6'sının 6. sinıf, \%29,8'inin 7. sinıf ve \%25,4'ünün 8. sinıf öğrencisi olduğu, \%60,5'inin düzenli olarak spor yaptığı ve \%39,5'inin spor yapmadığı belirleniştir.

Tablo 2'de katılımcıların sosyal beceri düzeylerine ilişkin tanımlayıcı istatistikleri verilmiştir.

Tablo 2. Öğrencilerin sosyal beceri düzeyleri

\begin{tabular}{lccccc}
\hline & $\mathrm{N}$ & En az & En çok & Ortalama & Std. Sapma \\
\hline Sosyal beceri ortalama & 114 & 37,00 & 79,00 & 58,2632 & 9,11777 \\
\hline
\end{tabular}

Tablo 2'de tüm öğrencilerin (n:114) sosyal beceri düzeylerinin $x=58,2( \pm 9,11)$ olduğu belirlenmiştir.

Tablo 3. Öğrencilerin spor yapma durumlarına göre sosyal beceri düzeyleri (t-testi).

\begin{tabular}{ccccccc}
\hline & $\begin{array}{c}\text { Spor yapma } \\
\text { durumu }\end{array}$ & N & Ortalma & Std. Sapma & t & p \\
\hline \multirow{2}{*}{ Sosyal Beceri } & Evet & 69 & 59,1594 & 9,88109 \\
\cline { 2 - 5 } & Hayır & 45 & 56,8889 & 7,70838 \\
\hline
\end{tabular}

Tablo 3'te öğrencilerin spor yapma durumlarına göre sosyal beceri düzeyleri belirlenmiştir. Spor yapan öğrencilerin sosyal beceri düzeyleri $x=59,15( \pm 9,88)$ spor yapmayanların sosyal beceri düzeyleri 56,88( $\pm 7,70)$ olarak belirlenmiştir. Bu bulgulardan öğrencilerin spor yapma durumlarına göre sosyal beceri düzeylerinde istatistiksel olarak anlamlı farklılığa rastlanmamıştır(p<0.05). 
Tablo 4. Öğrencilerin cinsiyet değişkenine göre spor yapma durumları ile ilgili sosyal beceri düzeyleri (independent samples t-test).

\begin{tabular}{llllllr}
\hline Cinsiyet & Spor yapma & N & \multicolumn{1}{c}{ x } & S. s. & \multicolumn{1}{c}{ P } \\
\hline \multirow{2}{*}{ Kadın } & \multirow{2}{*}{ Sosyal beceri } & Evet & 32 & 57,6250 & 8,07 & \\
\cline { 3 - 7 } & Hayır & 25 & 55,9600 & 5,26 & 376 \\
\hline \multirow{2}{*}{ Erkek } & \multirow{2}{*}{ Sosyal beceri } & Evet & 37 & 60,4865 & 11,14 & \\
\cline { 3 - 6 } & Hayır & 20 & 58,0500 & 10,00 & 418 \\
\hline
\end{tabular}

Tablo 4'te Spor yapan kadın öğrencilerin sosyal beceri düzeyleri $\mathrm{x}=57,62( \pm 8,07)$ spor yapmayan kadın öğrencilerin sosyal beceri düzeylerinin $x=55,96( \pm 5,26)$ olduğu belirlenmiştir. Spor yapan erkek öğrencilerin sosyal beceri düzeyleri $x=60,48( \pm 11,14)$ spor yapmayanların sosyal beceri düzeyleri $\mathrm{x}=58,05( \pm 10,00)$ olarak belirlenmiştir. Analizler sonucunda öğrencilerin cinsiyetlerine göre sosyal beceri düzeylerinde istatistiksel olarak anlamlı farklılık-olmadığı belirlenmiştir ( $\mathrm{p}>0.05$ ).

Tablo 5. Öğrencilerin Sınıf farklılığına göre sosyal beceri düzeyleri

\begin{tabular}{lccccc}
\hline Sinıf & N & $\begin{array}{c}\text { Sosyal Beceri Düzeyi } \\
\text { Ortalamas }\end{array}$ & S.S. & S. Hata & P \\
\hline 5 & 23 & 55,6522 & 8,53660 & 1,78000 & \\
\hline 6 & 28 & 61,1786 & 11,31388 & 2,13812 & 0,54 \\
\hline 7 & 34 & 56,1471 & 8,55333 & 1,46688 & \\
\hline 8 & 29 & 60,0000 & 6,77706 & 1,25847 & \\
\hline Total & 114 & 58,2632 & 9,11777 &, 85396 & \\
\hline
\end{tabular}

Tablo 5'te sınıf değişkenine göre öğrencilerin sosyal beceri düzeyi farklılıklarına bakılmıştır. Analizler sonucunda öğrencilerin sosyal beceri düzeylerinin sınıf faktörüne göre değişmediği bulunmuş̧ur ( $\mathrm{p}>0.05)$.

Tablo 6. Öğrencilerin sınıf değişkenine göre sosyal beceri düzeylerinin spor yapma durumlarına göre değerlerleri (Anova)

\begin{tabular}{|c|c|c|c|c|c|c|}
\hline & Sinif & $\mathbf{N}$ & $\begin{array}{c}\text { Sosyal } \\
\text { beceri ort. }\end{array}$ & SS & $\mathbf{F}(\mathbf{p})$ & $\begin{array}{c}\text { Farklılık } \\
\text { (LSD) }\end{array}$ \\
\hline \multirow{4}{*}{$\begin{array}{l}\text { Spor yapma } \\
\text { durumu evet }\end{array}$} & 5 & 16 & 56,25 & 8,92 & \multirow{4}{*}{0,34} & $5<6,7,8$ \\
\hline & 6 & 19 & 64,15 & 12,65 & & \\
\hline & 7 & 24 & 60,90 & 4,35 & & \\
\hline & 8 & 10 & 59,15 & 9,88 & & \\
\hline \multirow{4}{*}{$\begin{array}{l}\text { Spor yapma } \\
\text { durumu hayır }\end{array}$} & 5 & 7 & 53,42 & 7,74 & \multirow{4}{*}{,229 } & \\
\hline & 6 & 9 & 54,88 & 2,52 & & \\
\hline & 7 & 10 & 56,10 & 9,67 & & \\
\hline & 8 & 19 & 59,52 & 7,82 & & \\
\hline
\end{tabular}


Tablo 6'da öğrencilerin sınıf farklılığına göre sosyal beceri düzeyleri yer almaktadır. Analiz sonucunda öğrencilerin sosyal beceri düzeylerinde sınıf değişkenine göre istatistiksel olarak anlamlı farklılık görülmüştür $(\mathrm{p}<0.05)$. Spor yapan 5. sınıf öğrencilerinin sosyal beceri düzeyleri 6,7 ve 8 . Sinıf öğrencilerinden daha düşük olarak bulunmuştur. Spor yapmayan öğrencilerin sosyal beceri düzeylerinde sınıf değişkenine göre istatistiksel açıdan anlamlı farklılı̆̆a rastlanmamıştır. $(\mathrm{p}>0.05)$.

\section{TARTIŞMA VE SONUÇ}

İlk öğretim ikinci kademe de okuyan öğrencilerin spor yapma durumlarina göre sosyal becer düzeylerini belirlemek amacıyla yapılan bu çalışmada elde edilen bulgularla ilgili yorumlar aşağıda yer almaktadır. Çalışmaya katılan öğrencilerin yaşları 9-12 arasında değişmekte olup toplam 114 kişidir. Öğrencilerin \%50'si (n=57) kadın, \%50'si (n=57) erkektir. Düzenli olarak spor yapan öğrenci \% 60,50 $(n=69)$ spor yapamayan öğrenci ise 39,50 $(n=45)$ olarak belirlenmştir. Öğrencilerin \%20,2'si (n=23) 5. sinıf \%24,6'sı (n=28) 6. sınıf, \%29,8'i $(n=34) 7$. sinıf ve $\% 25,4^{\prime} \ddot{u}(n=29) 8$. sinıf öğrencisidir. Öğrencilerin \%60,5'I düzenli olarak spor yaptıklarını $(n=69) \quad \% 39,5^{\prime} i \quad(n=45)$ ise düzenli olarak spor yapmadıklarını söylemişlerdir. Elde edilen veriler sonucunda öğrencilerin spor yapma durumlarına göre istatistiksel açıdan anlamlı farklılığa rastlanmamıştır. Spor yapma durumlarına göre istatistiksel farklılık çıkmamasına ragmen spor yapan öğrencilerin sosyal beceri puanları spor yapmayn öğrencilere göre daha yüksek çıkmıştır. Çalışmada ulaşılan bir diğer sonuç, öğrencilerin cinsiyet değişkenine göre sosyal beceri düzeylerinde spor yapma durumları açısından istatistiksel olarak anlamlı farklılığa ulaşılmamıştır. Ayrıca çalışma sonucunda öğrencilerin sınıf değişkenine göre spor yapma durumları bakımından sosyal beceri düzeylerinde istatistiksel olarak anlamlı farklılığa rastlanmamıştır.

Öğretmenler özellikle fiziksel oyun ile öğrencilerin daha iyi iletişim kurduklarını ifade etmektedirler. Fiziksel Oyun esnasında çocuğun iletişim becerileri gibi sosyal becerileri olumlu yönde gelişmektedir (Samancı ve Diş, 2016). Literatüre baktığımızda bazı dikkat çekici sonuçlara ulaşılmıştır. Aghdasi'nin (2014), bireysel ve takım sporu yapan 216 öğrenci üzerinde yapmış olduğu çalışma sonucuna göre, takım sporu yapan öğrencilerin sosyal becerileri düzeyleri bireysel spor yapanlardan daha yüksek çıkmıştır. Benzer şekilde Gezer ve arkadaşlarının (2017) yapmış oldukları çalışmada çeşitli spor branşlardaki takım sporu yapan elit sporcuların sosyal beceri düzeylerinin daha yüksek olduğu belirlenmiştir. Bu çalışma sonucunda öğrencilerin spor yapma durumlarına göre sosyal becerilerinde anlamlı farklılığa rastlanmamasına ragmen spor yapan öğrencilerin sosyal beceri düzeyi ortalamaları spor yapmayanlardan daha yüksek bulunmuştur. Sonuçların bu şekilde çıkması diğer çalışmalarla kıyaslandığında örneklen sayısının az olmasından kaynaklanabileceği düşünülmektedir. Bunun yanında öğrencilerin gerçekten düzenli olarak spor yapıp, yapmamaları takip edilmeyip, verdikleri cevaplar doğrultusunda değerlendirilmiştir. $\mathrm{Bu}$ durumlar çalışmanın sınırlılıklarını oluşturmaktadır. 
Coşkun ve Samancı'nın (2012) 4. ve 5. sınıfta okuyan 300 öğrenci üzerinde yapmış oldukları çalışma sonucunda öğrencilerin sınıf düzeyine göre sosyal becerilerinde fark olduğu bulunmuştur. 5. sınıf öğrencilerinin sosyal becerilerinin 4. sınıf öğrencilerinden daha yüksek olduğuna ulaşılmıştır. Bu çalışmada ise spor yapan öğrencilerde sınıf farklılığına göre sosyal beceri düzeylerinde istatatisitksel açıdan anlamlı farklılığa rastlanmıştır. Benzer şekilde daha üst sınıflarda okuyan öğrencilerin sosyal beceri düzeyleri daha yüksek çıkmıştır. Düzenli spor yapan 6,7,8. Sınıf öğrencilerinin sosyal beceri düzeyleri 5. Sınıf öğrencilerinden daha yüksektir. Spor yapmayan öğrencilerde ise sınıf değişkenine göre farklılıklar bulunmamıştır.

Akpınar ve arkadaşlarının (2015), Beden Eğitimi ve Spor Yüksekokulunda okuyan öğrenciler üzerinde yapmış oldukları çalışma sonucunda öğrencilerin sosyal beceri düzeylerinin orta seviyede olup yaş, cinsiyet, okuduğu bölüm, kaldığı yer değişkenleri açısından istatistiksel olarak anlamlı fark bulunamazken, sınıf, anne ve babalarının eğitim durumu kardeş sayıları değişkenlerine göre ise istatistiksel olarak anlamlı bir fark bulunmuştur. Bu çalışmada da cinsiyet faktörüne göre öğrencilerin sosyal becerilerinde istatistiksel açıdan anlamlı farklılıklara rastlanmamıştır.

Makar'ın (2016) spor eğitimi gören öğrencilerin ( $n=453)$ sosyal beceri, fiziksel benlik algıs1 ve fiziksel aktivite düzeylerini araştırdığı çalışma sonucunda kadın ve erkek öğrencilerin sosyal beceri ile fiziksel benlik algısı ve fiziksel aktivite değerleri arasında pozitif ilişki bulunmuştur.

Öğrencilerin aktif olarak spor branşına katılma/katılmama durumları ile sosyal beceri düzeyleri arasındaki lişkiyi incelediğimiz çalışmada, öğrencilerin anket sorularına verdikleri yanıtlardan elde ettiğimiz verilere göre, aktif olarak spor yapıyor ya da yapmıyor olamaları sosyal beceri düzeylerinde anlamlı bir farklılık yaratmadığı çalışmamızın sonucu olarak söylenilebilmektedir. Fakat dikkat çekilmesi gereken diğer bir sonuç ise, istatistiksel olarak anlamlı bir farklılık olmamasına rağmen aktif olarak sportif bir faaliyet içerisinde olan çocukların sosyal beceri düzeylerinin daha yüksek olduğur. Spor ortamları özellikle ergenliğe geçiş sürecinde olan çocukların sosyalleşmeleri için en uygun ortamlardan biridir. Çocukların sportif etkinliklere daha fazla katılımını sağlamak amacıyla kendilerinin kararları ve istekleri doğrultusunda katılmak istedikleri spor branşlarına yönlendirilmeleri sporu hayatlarının bir parçası haline getirmelerine yardımcı olacaktır. Bu şekilde gönüllü ve aktif olarak katılacakları spor branşaları sağlanılırsa hem fiziksel becerilerine hemde sosyal becerilerine katkı sağlayacağı söylenebilir. 


\section{KAYNAKLAR}

Akpınar, S., Akpınar, Ö., Nas, K., Temel, V., \& Birol, S. S. (2015). Beden egitimi ve spor yüksekokulunda okuyan ögrencilerinin bazı degişkenler açısından sosyal beceri düzeylerinin incelenmesi. Sosyal ve Ekonomik Araştırmalar Dergisi, 17(28), 80.

Coşkun, N., Samanci, O. (2012). İlköğretim 4. ve 5. sınıflarda sosyal beceri düzeyi ile sosyal bilgiler dersine yönelik tutumların çeşitli değişkenler açısından incelenmesi. Journal of Educational and Instructional Studies in the World, 2(1), 32-41.

Çetin, F., Bilbay, A., Albayrak, \& Kaymak, D. (2013). Çocuklarda Sosyal Beceriler. İstanbul: Epsilon Yayınları.

Ergin, H. (2004). Okul öncesi dönem çocukları için iletişim becerileri ölçeklerinin geçerlilik, güvenirlik ve norm çalışması, Hasan Ali Yücel Eğitim Fakültesi Dergisi, 2, 181-199.

Gezer, E.D., Aslan, C.S., Dalkıran, O., \& Kilcigil E., (2017). Farklı spor branşlarındaki elit sporcuların sosyal beceri düzeylerinin seçilmiş değişkenler açısından karşılaştırılması. Mehmet Akif Ersoy Üniversitesi Sosyal Bilimler Enstitüsü Dergisi, 9 (22), 251-258.

Kocayörük, A. (2000). İlköğretim öğrencilerinin sosyal becerilerini geliştirmede dramanın etkisi. Yayınlanmamış Yüksek Lisans Tezi, Ankara Üniversitesi: Sosyal Bilimler Enstitüsü, Ankara.

Makar, E., (2016). Spor ĕgitimi gören öğrencilerin, sosyal beceri, fiziksel benlik alglsl ve fiziksel aktivite düzeyleri arasındaki ilişkinin incelenmesi. Bartın Üniversitesi Eğitim Bilimleri Enstitüsü, Beden Eğitimi ve Spor Öğretmenliği Anabilim Dalı, Yayınlanmamış Yüksek Lisans Tezi.

Aghdasi M., T., (2014). Çeşitli spor kadin atlet öğrencilerinin sosyal beceri değerlendirilmesi. Uluslararası Hakemli Akademik Spor Sağlik ve Tıp Bilimleri Dergisi, 13 (4), 134-142.

Orhan, R., (2019). Çocuk gelişiminde fiziksel aktivite ve sporun önemi. Kırıkkale Üniversitesi Sosyal Bilimler Dergisi, 9 (1), 157-176.

Samancı, O. \& Diş, O. (2016). Sosyal becerileri zayıf olan ilkokul öğrencilerinin tutum ve davranışlarının öğretmen görüşlerine göre değerlendirilmesi. Kastamonu Eğitim Dergisi, 22(2), 573-590.

Strauss, R.S., Rodzilsky, D., Burack, G. \& Colin, M. (2001). Psychosocial correlates ofphysical activity in healthy children. Arch Pediatr Adolesc Med, 155, 897-902.

T.C. Sağlık Bakanlığı (2014). Türkiye Beslenme ve Sağlık Araştırması 2010: Beslenme Durumu ve Alışkanlıklarının Değerlendirilmesi Sonuç Raporu. Ankara, Sağlık BakanlığI Sağlık Araştırmaları Genel Müdürlüğü.

T.C. Sağlık Bakanlığg (2011). Türkiye'de okul çağı çocuklarında (6-10 yaş grubu) büyümenin izlenmesi (toçbi) projesi araştırma raporu. Ankara, Sağlık Bakanlığı Temel Sağlık Hizmetleri Genel Müdürlüğü.

Walker, H.M. \& McConell, S.R. (1995). Walker-McConnell Scale of Social Competence and School Adjustment: Elementary Version. London: Singular Publishing Group. 